\title{
Experimental Study on Performance of Double pipe Length on Instantaneous Air Source Heat Pump Water Heater
}

\author{
Yin Shaoyou ${ }^{1, \text { a }}$ \\ ${ }^{1}$ Heat Pump Engineering and Technology Development Center of Guangdong Universities, Shunde \\ Polytechnic, Foshan Guangdong 528333, China \\ a168yyy@163.com
}

Keywords: Heat pump water heater, Double pipe condenser, Length, Performance, Energy efficiency ratio.

Abstract. The performance of the instantaneous air-source heat pump water heaters which is made of the different double pipe heat exchangers respectively was studied, the influence of double-pipe inner wall thickness on the heat transfer area, the water flow velocity, the heat transfer coefficient, and the water system resistance of the double pipe heat exchanger was analyzed, and the influence of double-pipe inner wall thickness on heat pump water heater performance was studied in this paper. The experimental results show that: the energy efficiency of heat pump water heater is improved by the appropriate design of double pipe length, in addition, the heat capacity can be increased, and power consumption can be reduced.

\section{Introduction}

Most residential water heaters are equipped with conventional heaters generating heat by consuming fossil fuels or electricity. Those water heaters are usually simple, but not desirable in view of energy utilization efficiency. For instance, electric water heaters are convenient for installation and operation, however, the overall efficiency in converting a potential energy of fossil fuels into electric energy, then into thermal energy is quite low. Compared to those water heaters, heat pump water heating systems can supply much more heat just with the same amount of electric input used for conventional heater[1]. To produce the same amount of hot water conditions, the energy consumption of air source heat pump water heater is only $1 / 4$ of electric water heater, and 1/3 of gas water heater, and 1/2 of electric assisted solar water heater, so it has great potential in energy saving. Air source heat pump water heater as a new product, has the characteristics of high efficiency, energy saving and environmental protection etc., It is becoming the mainstream products in domestic and foreign water heater industry. In order to study the performance of air source heat pump water heater, some domestic and foreign scholars have made a series of research on the air source heat pump water heater. Minsung Kim etc. [1] study on the heat transfer characteristics of water source heat pump water heater, J. Sarkar etc. [2] study on the characteristics of the high temperature heat pump water heater natural working substance, Pei Gang etc. [3] analyses the performance of instantaneous air source heat pump water heater and circulating heat air source heat pump water heater, Fan Xiaowei etc. [4] study on the influence of mixture of R744 and R290 on the heat pump water heater, Zhang Jie etc. [5] system optimization calculation and experimental research of air sourced heat pump water heater. Hao Jibo etc. [6] test and simulate the performance of static heat air source heat pump water heater. The air source heat pump water heater for one horsepower to two horsepower are widely used in domestic air source heat pump water heater. Therefore, it has great competitive potential market and very good market prospects for double pipe instantaneous air source heat pump water heater. The performance of the two horsepower double pipe instantaneous air source heat pump water heater was tested in this paper, the research results will provide the reference and technical support on the air source heat pump water heater design. 


\section{Experimental Setup}

This experiment testing principle shows in Figure 1. The temperature sensor uses the $\mathrm{T}$ type thermocouple. Pressure sensor range is $0 \mathrm{MPa}-4 \mathrm{MPa}$, precision is $0.5 \%$; Flow rate sensor with Dalian KRC Inc. KRC-1518H time single channel ultrasonic liquid flow sensor, The velocity range is $0.01 \mathrm{~m} / \mathrm{s}-30 \mathrm{~m} / \mathrm{s}$, the flow accuracy is $\pm 0.5 \%$. The experimental tests were performed at the laboratory of heat pump water heater, the environmental working conditions of the laboratory is $-10^{\circ} \mathrm{C}$ to $50^{\circ} \mathrm{C}$. Test nominal working condition is: The air side air dry bulb temperature is $20^{\circ} \mathrm{C}$, the wet bulb temperature is $15^{\circ} \mathrm{C}$; Water side entering water temperature is $15^{\circ} \mathrm{C}$, the leaving water temperature is $55^{\circ} \mathrm{C}$. The products of 6 different double pipe heat exchangers are made of the double pipes which is $0.7 \mathrm{~mm}$ thickness the inner tube wall, $1630 \mathrm{~mm}-2580 \mathrm{~mm}$ expansion length the double pipe, $130 \mathrm{~mm}$ $-170 \mathrm{~mm}$ height double pipe heat exchanger. The products of 6 different double pipe instantaneous air source heat pump water heaters are made of the products of 6 different double pipe heat exchangers respectively. The double pipe instantaneous air source heat pump water heater is test, and the parameters of double pipe instantaneous air source heat pump water heater for heat, power, power consumption, $\mathrm{COP}$ (coefficient of performance), temperature, pressure, flow rate etc. are recorded. It uses Guangzhou Panasonic Corp of rotary compressor, which is model 2V32S225AUA, and the rated cooling capacity $5375 \mathrm{~W}$, and rated power $1700 \mathrm{~W}$, and refrigerant R22 in the double pipe instantaneous air source heat pump water heater. The pump rated flow is $3 \mathrm{~m}^{3} / \mathrm{h}$. The motor of fan is YDK120-40-6A, rated power is $40 \mathrm{~W}$, the fan impeller specification is $\Phi 420 \times 148$. The double pipe heat exchanger shows in figure 2, the inner pipe and the outer pipe of double pipe is brass, the brass brand is TP2M; the outer diameter of the outer copper pipe in the double pipe is $\Phi 15.88 \mathrm{~mm}$, the thickness of the outer copper wall is $0.5 \mathrm{~mm}$; the outer diameter of the inner copper pipe in the double pipe is $\Phi 9.52 \mathrm{~mm}$, the thickness of the inner pipe wall are is $0.7 \mathrm{~mm}$. The outer pipe wall of the double pipe heat exchanger is used PE thermal insulation pipe, the thermal insulation layer thickness is $10 \mathrm{~mm}$. Water flows passage of the inner tube inside, and the refrigerant flows in the ring channel between the outer tube and inner tube. The evaporator is $L$ type and double row aluminum finned, the brass brand is TP2M, the outer diameter of the brass pipe is $\Phi 9.52 \mathrm{~mm}$, the thickness of the hydrophilic finned aluminum is $0.095 \mathrm{~mm}$. EMERSON throttle valve is used, its type is AAE2HC-30FT, the superheat degree of the refrigeration circulation is adjusted.

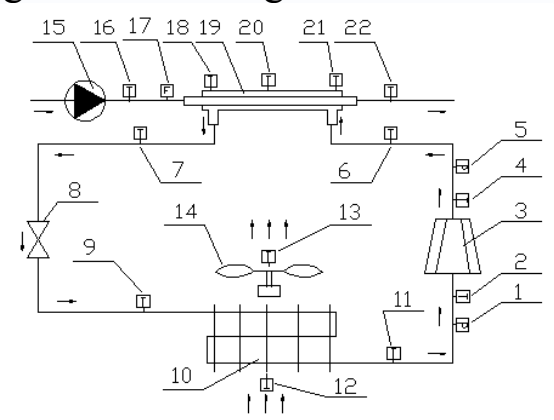

1,5 -pressure sensor $2,4,6,7,9,11,12,13,16,18,20,21,22$-temperature sensor

3 -compressor 8 -throttle valve 10 - finned evaporator 14-fan 15 -Variable frequency pump 17-Flow sensor 19-double pipe heat exchanger

Fig.1 Schematic diagram of air source heat pump water heater test systems

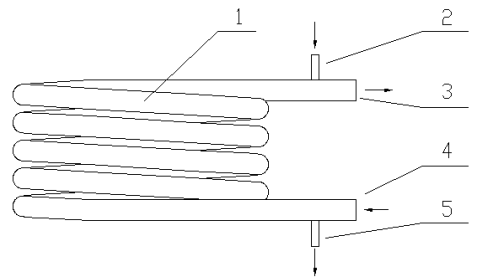

$1-$ double pipe heat exchanger $2-$ refrigerant entering $3-$ heat water leaving

4 - cold water entering $\quad 5$-refrigerant leaving

Fig.2 The double-pipe condenser of air source heat pump water heater 


\section{Data processing}

The products of 6 different double pipe heat exchangers are made of the double pipes which are $0.7 \mathrm{~mm}$ thickness the inner tube wall, $1630 \mathrm{~mm}-2580 \mathrm{~mm}$ expansion length the double pipe, $130 \mathrm{~mm}$ $-170 \mathrm{~mm}$ height double pipe heat exchanger. The products of 6 different double pipe instantaneous air source heat pump water heaters are made of the products of 6 different double pipe heat exchangers respectively. The double pipe instantaneous air source heat pump water heater is tested, and the power, temperature, water flow are recorded in the experiment, the double pipe instantaneous air source heat pump water heater energy efficiency ratio can be calculated, the calculation formula is as follows:

$$
\operatorname{COP}=\frac{q_{i s}}{W}
$$

Where $Q_{s}$-heat capacity of heat pump water heater, W; W-power consumption of heat pump water heater, $\mathrm{W}$.

$$
\mathrm{Q}_{\mathrm{c}}=\mathrm{RA \Delta \textrm {t } _ { \mathrm { m } }}
$$

Where K-heat transfer coefficient of double pipe heat exchanger, $\mathrm{W} /\left(\mathrm{m}^{2} .{ }^{\circ} \mathrm{C}\right)$; A-heat transfer

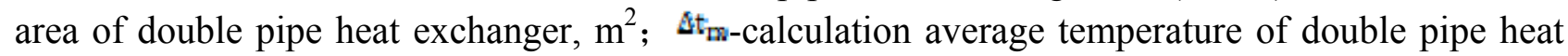
exchanger, ${ }^{\circ} \mathrm{C}$.

\section{Results and discussion}

The double pipe heat exchanger is made of the double pipes which is $0.7 \mathrm{~mm}$ thickness the inner tube wall, $2200 \mathrm{~mm}$ expansion length the double pipe, $170 \mathrm{~mm}$ height double pipe heat exchanger. The double pipe instantaneous air source heat pump water heater is made of the double pipe heat exchanger. The double pipe instantaneous air source heat pump water heater is tested, and the parameters of double pipe instantaneous air source heat pump water heater for COP(coefficient of performance), heat capacity are recorded. Test working condition is: the air side air dry bulb temperature is $-5^{\circ} \mathrm{C}$ to $45^{\circ} \mathrm{C}$, water side entering water temperature is $15^{\circ} \mathrm{C}$, the leaving water temperature is $55^{\circ} \mathrm{C}$. The energy efficiency ratio $\mathrm{COP}$ and the heat capacity of double pipe instantaneous air source heat pump water heater are concern of the different environment temperatures, as shown in figure3- figure 4. As the ambient air dry bulb temperature to rise, the energy efficiency ratio COP and the heat capacity of the double pipe instantaneous air source heat pump water heater are increased gradually; When the ambient air dry bulb temperature is $20^{\circ} \mathrm{C}$, it is the highest energy efficiency ratio COP and the highest heat capacity. As the ambient air dry bulb temperature continues to rise, energy efficiency ratio COP and heat capacity are reduced gradually.

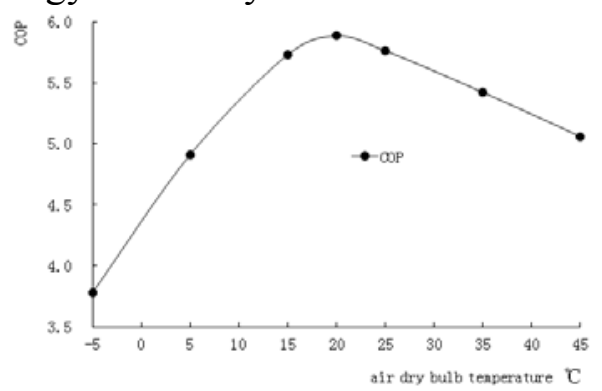

Fig.3 The COP value of air source heat pump water heater with different ambient air dry bulb temperature

The products of 6 different double pipe heat exchangers are made of the double pipes which are $0.7 \mathrm{~mm}$ thickness the inner tube wall, and $1630 \mathrm{~mm}, 1820 \mathrm{~mm}, 2010 \mathrm{~mm}, 2200 \mathrm{~mm}, 2390 \mathrm{~mm}$, $2580 \mathrm{~mm}$ expansion length the double pipe, and $130 \mathrm{~mm}-170 \mathrm{~mm}$ height double pipe heat exchanger. The products of 6 different double pipe instantaneous air source heat pump water heaters are made of the products of 6 different double pipe heat exchangers respectively. 


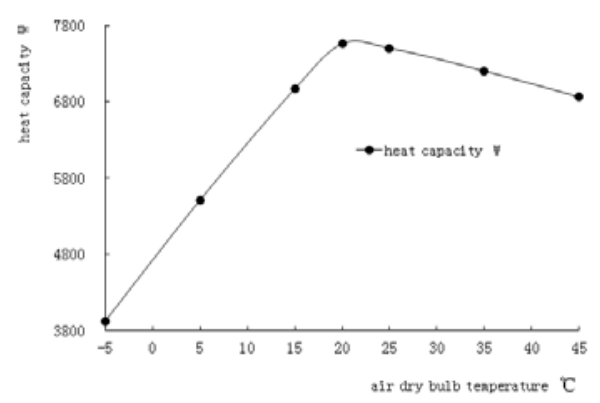

Fig.4 The heat capacity of air source heat pump water heater with different ambient air dry bulb temperature

In figure5- figure6, the water side heat transfer area and the water flow velocity of the double pipe heat exchanger are concern of the double pipe expansion length. As the expansion length of the double pipe is increased, the water side heat transfer area of the double pipe is increased, the water flow velocity is increased, the convection heat transfer coefficient of copper pipe inner wall surface water side is increased in double pipe heat exchanger, the heat transfer coefficient of double pipe heat exchanger is increased. Therefore, the degree of supercool is gradually increased, and the degree of superheat is gradually reduced in the refrigeration circulation. At the same time, the resistance of water pipe system is increased, the operation efficiency is reduced, and the cost is increased in the double pipe instantaneous air source heat pump water heater.

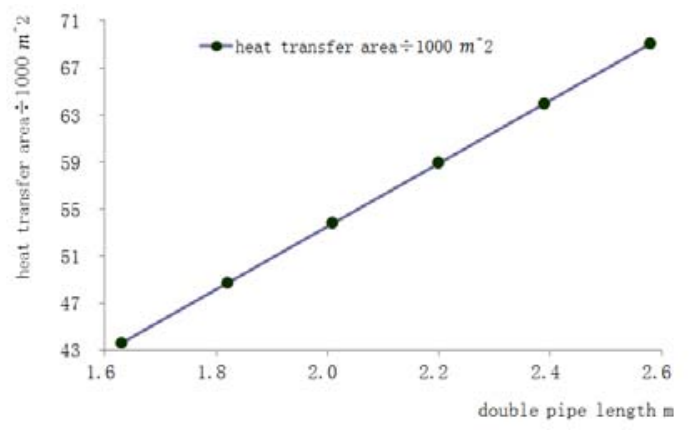

Fig.5 The water side heat transfer area of the double pipe heat exchanger with double-pipe length

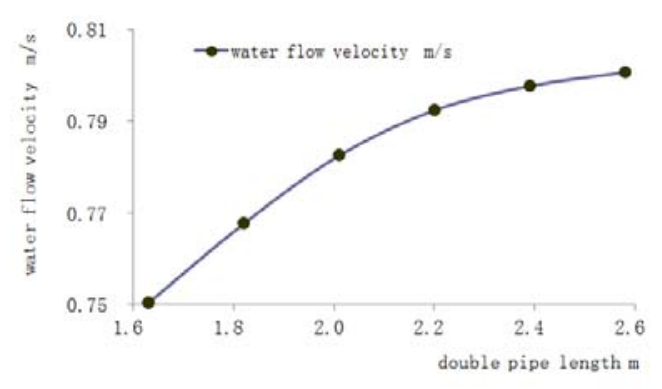

Fig.6 The water flow velocity of the double pipe heat exchanger with double-pipe length

See figure7-figure8, the energy efficiency ratio COP and the heat capacity of the double pipe instantaneous air source heat pump water heater are concern of the double pipe expansion length under a test nominal working condition. In figure7, as the expansion length of the double pipe is increased, the heat transfer area of the double pipe heat exchanger is increased, the energy efficiency ratio COP of double pipe instantaneous air source heat pump water heater is increased gradually. When the double pipe expansion length is $2200 \mathrm{~mm}$, it is the highest energy efficiency ratio COP. As the expansion length of the double pipe continues to increase, the energy efficiency ratio COP is gradually reduced. 
In figure 8, as the expansion length of the double pipe is increased, the heat transfer area of the double pipe heat exchanger is increased, the heat capacity of double pipe instantaneous air source heat pump water heater is increased gradually. As the expansion length of the double pipe continues to increase, the increase of heat capacity is gradually decreased.

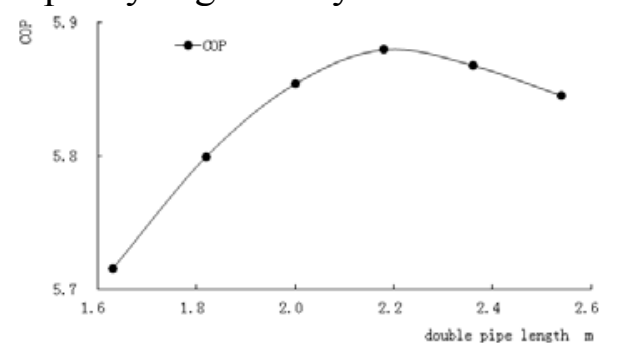

Fig.7 The COP value of air source heat pump water heater with double-pipe length

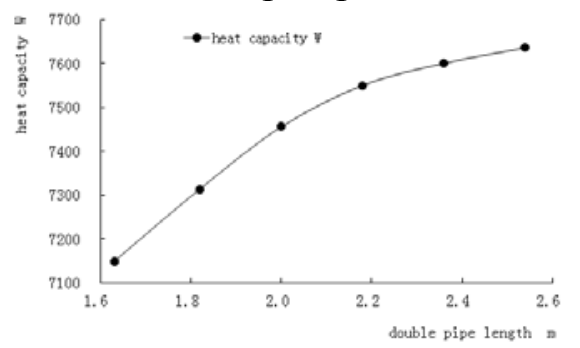

Fig. 8 The heat capacity of air source heat pump water heater with double-pipe length

\section{Conclusion}

(1) As the expansion length of the double pipe is increased, the water side heat transfer area of the double pipe is increased, the water flow velocity is increased, the heat transfer coefficient of double pipe heat exchanger is increased, the resistance of water pipe system is increased, the operation efficiency is reduced, and the cost is increased in the double pipe instantaneous air source heat pump water heater.

(2) As the expansion length of the double pipe is increased, the energy efficiency ratio COP of double pipe instantaneous air source heat pump water heater is increased gradually. When the double pipe expansion length is $2200 \mathrm{~mm}$, it is the highest energy efficiency ratio COP. As the expansion length of the double pipe continues to increase, the energy efficiency ratio COP is gradually reduced.

(3) As the expansion length of the double pipe is increased, the heat capacity of double pipe instantaneous air source heat pump water heater is increased gradually. As the expansion length of the double pipe continues to increase, the increase of heat capacity is gradually decreased.

(4) As the ambient air dry bulb temperature to rise, the energy efficiency ratio COP and the heat capacity of the double pipe instantaneous air source heat pump water heater are increased gradually; When the ambient air dry bulb temperature is $20^{\circ} \mathrm{C}$, it is the highest energy efficiency ratio COP and the highest heat capacity. As the ambient air dry bulb temperature continues to rise, energy efficiency ratio COP and heat capacity are reduced gradually.

\section{Acknowledgments}

This work was supported by the National Science Foundation of China (No.51576136) and Project of Foshan City Science and Technology Innovation Foundation (No. 2013AG100063).

\section{References}

[1] Minsung Kim, Min Soo Kim, Jae Dong Chung. Transient thermal behavior of a water heater system driven by a heat pump[J].International Journal of Refrigeration,2004, (27) : 415-421. 
[2] J. Sarkar, Souvik Bhattacharyy, M. Ram Gopal. Natural refrigerant-based subcritical and transcritical cycles for high temperature heating [J]. International Journal of Refrigeration, 2007, (30):3-10.

[3] Pei Gang, Li Guiqiang, Ji Jie. Comparative study of air-source heat pump water heater systems using the instantaneous heating and cyclic heating modes[J]. Applied Thermal Engineering,2011(31):342-347.

[4] Fan Xiaowei, Zhang Xiaojing, Zhang Xianping, Wang Fang. Influence of mixture of R744 and R290 in small mass fraction on the system performance of heat pump water heater [J], Energy Conservation Technology, 2014, 32(187):434-438.

[5] Zhang Jie, Zhang Liangjun, Wang Ruzhu, Wu Jingyi. System optimization calculation and experimental research of air sourced heat pump water heater[J]. Acta Energiae Solaris Sinica, 2007, 28(3): 286-289.

[6] Hao Jibo, Wang Zhihua, Jiang Yuguang, Wang Fenghao. Analysis of system performance of air source heat pump water heater [J]. Refrigeration and Air Conditioning, 2013, 13 (1):59-62. 